\title{
Batch waste gasification technology: characteristics and perspectives
}

\author{
P. De Filippis ${ }^{1}$, M. Scarsella ${ }^{1}$, N. Verdone $^{1} \&$ G. B. Carnevale ${ }^{2}$ \\ ${ }^{I}$ Chemical Engineering Department, Sapienza University of Rome, Italy \\ ${ }^{2}$ Energo s.r.l., Italy
}

\begin{abstract}
The problem of municipal solid waste (MSW) disposal is expanding rapidly in all the countries as a consequence of the habits and lifestyles of modern consumers that cause a continuous increasing volume of waste. To date, landfills are still the primary destination of waste. However, with landfill tipping fees rising and their proven negative environmental impacts, cleaner and less costly alternatives for municipal waste disposal should be identified and implemented. The energy recovery from MSW, known as "waste-to-energy" (WTE), is one of such alternatives. Waste-to-energy reduces the amount of materials sent to landfills, prevents air/water contamination, improves recycling rates and lessens the dependence on fossil fuels for power generation. The centrality of thermal processes in the WTE practice, makes strongly necessary the evaluation of the problems associated with both the release and formation of contaminants and the degree of pre-processing required in conversion of MSW into a suitable feed material. Among the currently WTE technologies, one that is finding some interest in Italy is the so called "Molecular Dissociation". This technology developed by Energo is claimed for some advantages, the main of which are the possibility to use as feed material unsorted MSW, the low emission level, and particularly the high flexibility due to its modular design that makes the process well adaptable to the seasonal changes and population growth. An experimentation conducted in a pilot plant greatly contributed to understand the behaviour of the process. On the basis of the obtained experimental results, the paper illustrates advantages and disadvantages of this technology.
\end{abstract}

Keywords: waste gasification, thermal processes, batch processes, MSW. 


\section{Introduction}

Accelerated economic development of many regions of the world in recent decades and the changes in the consumption patterns of modern lifestyle have resulted in a continuous increasing volume of waste, exasperating the problems related with municipal solid waste (MSW) disposal.

Notwithstanding the growing difficulties of many cities to find sites where to dispose the large quantities of MSW produced daily, to date landfills are still the primary destination of waste worldwide. However, landfill tipping fees rising and their proven negative environmental impact have substantially changed the processing of MSW, improving the landfill efficiency and implementing cleaner and less costly alternatives for MSW disposal.

The MSW processing is, in fact, now focused in reducing the amount of materials going into the landfill using an integrated strategy that involves various actors of the waste chain. This strategy begins with source reduction modifying how product are made, and continues increasing material recycling by converting it into reusable products, and treating the waste through thermal processes before entering the landfill. In this strategy thermal processing remains a functional piece of the MSW puzzle because of the ability to reduce feedstock by an average of $90 \%$ in volume and $75 \%$ in weight and because these processes can help the cost balance of MSW management [1].

Thermal processes are also at the base of the so called "waste-to-energy" (WTE) practice that beside the reduction of the amount of materials sent to landfill, prevents air/water contamination, improves recycling rates and lessens the dependence on fossil fuels for power generation. The two most commercially available forms of large scale WTE are combustion and gasification.

Combustion is a well-established practice, largely used in all the country around the world. In Europe with more than 50 million tons treated each year it accounts for an energy of about 20 million of MWh [2]. However, during combustion, dioxins and furans can form in the flue gas as they leave the combustion chamber and cool to $600-300^{\circ} \mathrm{C}$. These dioxins and furans, although captured before flue gas leaves the plant, are the primary catalyst for political and environmental opposition to the expansion of the WTE industry.

Alternative to combustion is gasification. This technology is still in its early stages as a large commercial industry, but is claimed to represent the next evolution in the thermal processing of MSW.

A technology in the middle between gasification and combustion is that developed by Energo with the trade mark name of "Molecular Dissociation". This WTE technology, is now finding some particular interest in Italy. Objective of this paper is to critically analyze this technology also considering the results of an experimentation conducted in a pilot plant.

\section{MSW thermal treatments}

It is generally accepted that MSW represents a material very difficult to handle, segregate and feed in a controlled manner to a waste-to-energy facility. 
Moreover MSW has a high tendency to form fused ash deposits on the internal surfaces of furnaces and high temperature reactors, and to form bonded fouling deposits on heat exchanger surfaces.

The products of the thermal treatments of MSW are also very aggressive, the flue gases are erosive and depending by the considered process can contain tars, heavy metals, halogens and alkaline compounds responsible of environmental and operational problems. Furthermore in the case of combustion the relatively high levels of chloride containing species in the flue gases can lead, other than to the formation of dioxins and furans, to high rates of metal wastage of heat exchange tube surfaces due to high temperature corrosion.

As a consequence, the key to achieve cost efficient, clean energy recovery from municipal solid waste will be evaluating the problems associated with both the release and formation of contaminants and the degree of pre-processing required in conversion of MSW into a suitable feed material.

Unsorted MSW is not suitable for most thermal technologies because of its varying composition and size of some of the constituent materials, and owing to the presence of undesirable materials which can negatively affect the process or the emission control systems.

The purpose of pre-processing is to produce a feed material with consistent physical characteristics and chemical properties. Pre-processing operations are also designed to produce a material that can be safely handled, transported and stored.

\subsection{The MSW gasification process}

The increasing technical, environmental and public dissatisfaction with the performance of conventional combustion (incineration) processes is the main reason for the growing popularity of gasification processes for the treatment of solid wastes [3]. There are numerous solid waste gasification facilities operating or under construction around the world.

Gasification is a process that devolatilizes solid or liquid hydrocarbons, and converts them into a low or medium calorific value gas. Two processes must take place in order to produce a useable fuel gas. In the first stage, pyrolysis releases the volatile components of the fuel at temperatures below $600^{\circ} \mathrm{C}$. The by-product of pyrolysis that is not vaporized is called char and consists mainly of fixed carbon and ash. In the second gasification stage, the carbon remaining after pyrolysis is either reacted with steam or hydrogen or combusted with air or pure oxygen.

Gasification has several advantages over traditional combustion of MSW. It takes place in a low oxygen environment that limits the formation of dioxins and of SOx and NOx. Furthermore, it requires just a fraction of the stoichiometric amount of oxygen necessary for combustion. As a result, the volume of process gas is low, requiring smaller and less expensive gas cleaning equipment. The lower gas volume also means a higher partial pressure of contaminants in the offgas, which take easier the complete adsorption and the particulate capture. Finally, gasification generates a fuel gas that can be integrated with combined 
cycle turbines, reciprocating engines and, potentially, with fuel cells that convert fuel energy to electricity more efficiently than conventional steam boilers.

\section{The batch gasification systems}

Although thermal processes are generally continuous, a certain interest is actually emerging for batch processes.

The two batch gasification systems that are earning some commercial success are the "Brookes Gasification Process" (BGP) and the "Batch Oxidation System" or "Molecular Dissociation".

The BGP technology is based on a fixed-bed, indirectly-heated, batch-fed gasifier, suitable for processing a wide range of feedstock materials, including swine manure solids. The BGP gasifier, more correctly seen as a pyrolyzer, consists of two chambers: a burning chamber and a 'gasification' chamber. Hot gases from the burning chamber heat the refractory bricks that line each of the two chambers, while the feedstock (e.g., separated swine solids) sits undisturbed on the hearth of the gasification chamber where it is indirectly heated to 600$1000^{\circ} \mathrm{C}$ by heat transfer [4].

In this way the feedstock is broken down into low molecular weight gases and volatile hydrocarbons, which are subsequently drawn into the burner chamber. Energy from these out-gases provides fuel that can sustain the entire gasification process. This process, initially designed as a cremator, evolved into an efficient system for the safe disposal of biohazard waste. However, it does not permit energy recovery and for its construction characteristics is not suitable for treating the large amount of MSW produced daily, even from a small town.

The "Molecular Dissociation" system, on the contrary, was specifically designed for the thermal treatment of small amount of untreated waste. Also in this technology the process is conducted using two stages (chambers): a batch gasification stage and a batch or continuous oxidation stage. The gasification occurs as a result of a partial oxidation process using substoichiometric combustion. The untreated solid waste is initially loaded into a primary chamber where it is thermally reacted under starved-air conditions and transformed into burnable gases and ash. Unlike typical thermal treatment methods, the gasification reactions occur at relatively low temperatures $\left(450-550^{\circ} \mathrm{C}\right)$ under quiescent conditions. The process is initiated by an ignition burner, situated towards the top of the gasification chamber. Once the gasification has commenced, this burner is turned off and the thermal process continues, controlled by the input of a small amount of air from the base of the chamber. The low gasification temperature minimizes the production of airborne 'fly ash' particulates, carryover of toxic metals, and NOx. The gasification process ensures nearly $100 \%$ burn-out of the waste and the by-product white ash with minimal residual carbon. Metals and glass in the waste remain unmelted with the ash in inert form and can be recovered by conventional recycling methods.

The combustible gases produced in the gasification chamber enter the secondary combustion chamber where they are mixed with further air (secondary air) and oxidized at much higher temperatures $\left(850-1200^{\circ} \mathrm{C}\right)$ which ensure the 


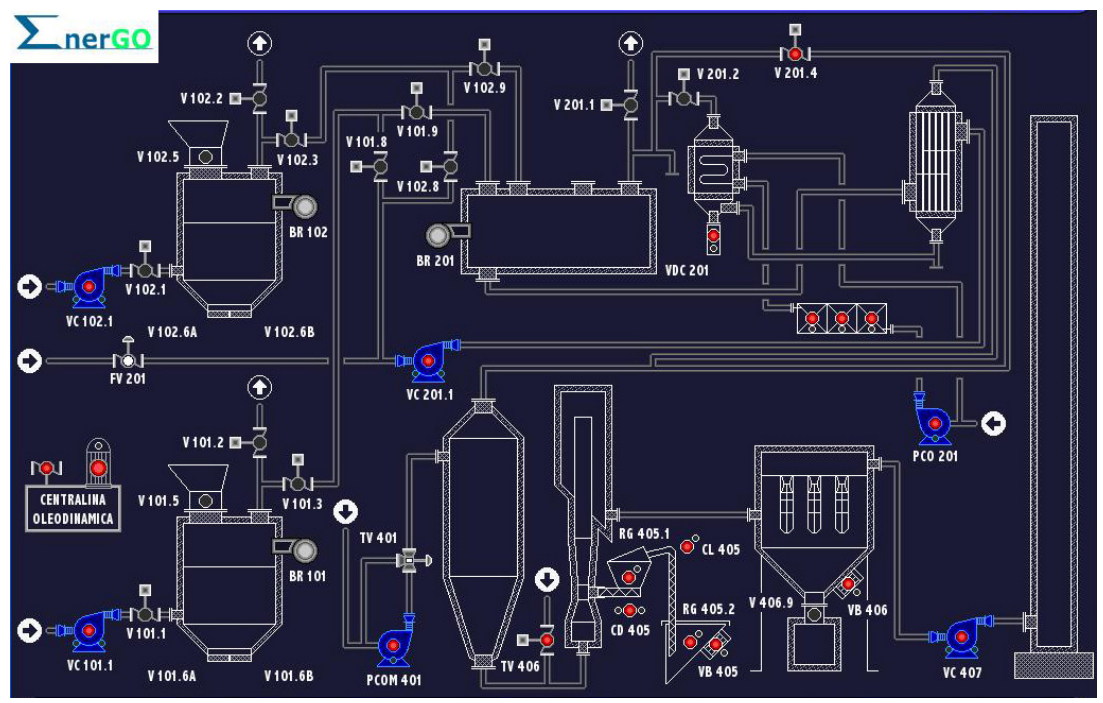

Figure 1: General scheme of the pilot plant.

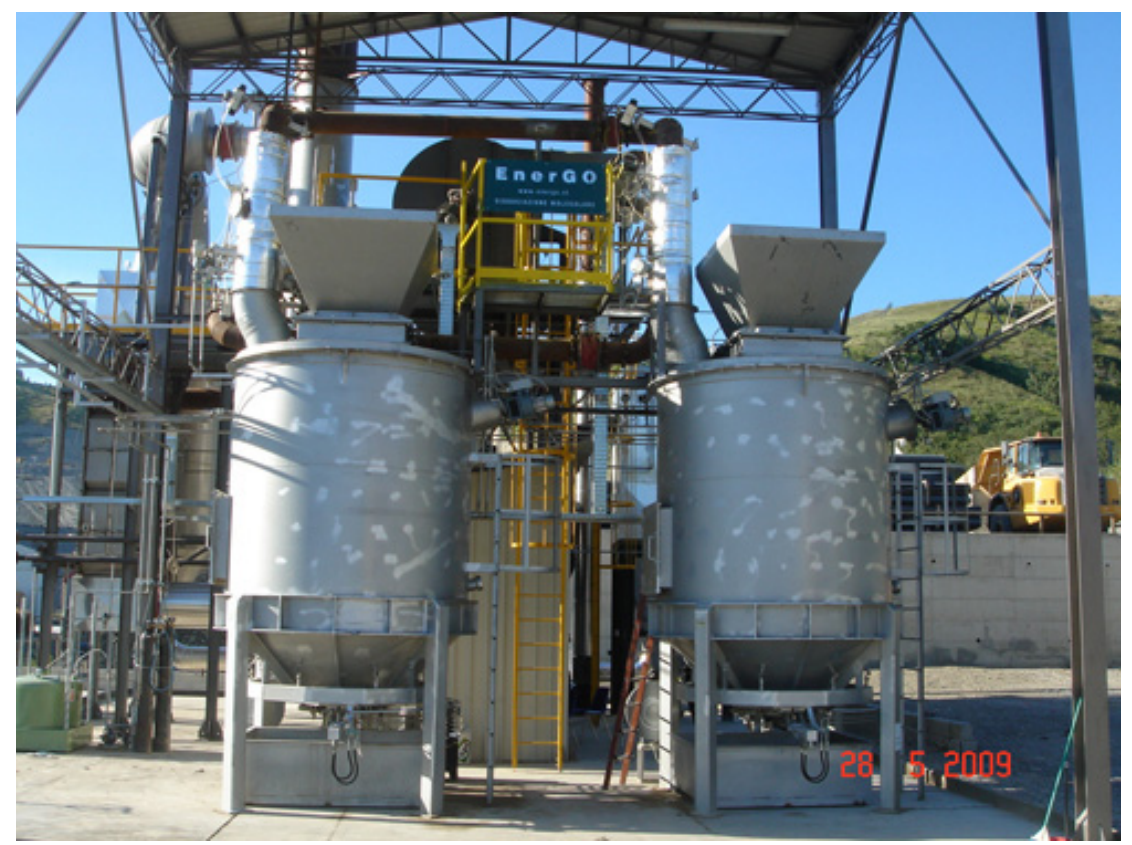

Figure 2: $\quad$ Picture of the pilot plant.

complete combustion. The gases in general can support this process, however a secondary burner ensures that minimum temperatures are maintained.

The energy from hot gas effluent can be recovered and used to produce steam and electricity. 
A "Molecular Dissociation" pilot plant designed and constructed by Energo is sited in Peccioli inside the Belvedere SpA landfill. The plant consist of two gasification chambers each with a capacity of $8 \mathrm{~m}^{3}$, of an oxidation chamber designed to assure a permanence time of at least two second at temperature higher than $850^{\circ} \mathrm{C}$, in accordance with the Italian legislation, and of a flue gas treatment system.

The general scheme is reported in Figure 1, while Figure 2 reports a picture of the pilot plant with the two gasification chambers in foreground.

The plant works with unsorted MSW, whose main physico-chemical characteristics are reported in Table 1.

Table 1: $\quad$ Main physico-chemical characteristics of the charged MSW.

\begin{tabular}{cc|cc}
\hline \multicolumn{2}{c|}{ Parameter } & Metal analysis & $\mathrm{mg} / \mathrm{kg}$ \\
\hline Low heating value (MJ/kg) & 11.8 & $\mathrm{Al}$ & 1881.23 \\
Water (\%wt) & 15.4 & $\mathrm{As}$ & 1.00 \\
Ash (\% dry wt) & 12.6 & $\mathrm{Ba}$ & 65.36 \\
& & $\mathrm{Cd}$ & 1.03 \\
Elemental analysis & & $\mathrm{Cr}$ & 25.76 \\
(dry basis) & & $\mathrm{Fe}$ & 3197.05 \\
$\mathrm{C}(\% \mathrm{wt})$ & 50.42 & $\mathrm{Mg}$ & 83.03 \\
$\mathrm{O}(\% \mathrm{wt})$ & 27.87 & $\mathrm{Hg}$ & 0.10 \\
$\mathrm{H}(\% \mathrm{wt})$ & 5.85 & $\mathrm{Ni}$ & 12.11 \\
$\mathrm{~N}(\% \mathrm{wt})$ & 1.69 & $\mathrm{~Pb}$ & 57.10 \\
$\mathrm{Cl}(\% \mathrm{wt})$ & 1.35 & $\mathrm{Cu}$ & 25.09 \\
$\mathrm{~S}(\% \mathrm{wt})$ & 0.23 & $\mathrm{~V}$ & 7.67 \\
$\mathrm{~F} \mathrm{(mg/kg)}$ & 73.8 & $\mathrm{Zn}$ & 95.39 \\
\hline
\end{tabular}

Table 2: $\quad$ Metals composition of the discharged ashes.

\begin{tabular}{cc}
\hline Metal analysis & $\mathrm{mg} / \mathrm{kg}$ \\
\hline $\mathrm{Al}$ & 14310 \\
$\mathrm{As}$ & 4.25 \\
$\mathrm{Ba}$ & 629.3 \\
$\mathrm{Cd}$ & 3.7 \\
$\mathrm{Cr}$ & 335.17 \\
$\mathrm{Fe}$ & 13596 \\
$\mathrm{Mg}$ & 429.3 \\
$\mathrm{Hg}$ & - \\
$\mathrm{Ni}$ & 119.10 \\
$\mathrm{~Pb}$ & 268.27 \\
$\mathrm{Cu}$ & 958.4 \\
$\mathrm{~V}$ & 26.34 \\
$\mathrm{Zn}$ & 2962.9 \\
\hline
\end{tabular}

The ash discharged at the end of the process contains low amounts of unburned carbon (typically less than 3\%), and high amounts of metals. The main metals composition of the discharged ashes is reported in Table 2 . 
The gas composition at the exit of the oxidation chamber before entering the gas treatment system is characterized by a low amount of total particulate, generally less than $10 \mathrm{mg} / \mathrm{Nm}^{3}$ and by a very low content of metals.

The quite total recovery of metals in the ash is compatible with the low temperature reached in the gasification chamber.

\section{Critical analysis of the "Molecular Dissociation"}

The experimental results confirm the interesting characteristics of the studied process that thanks to the combination of low gasification temperature and almost quiescent conditions allows one to minimize the problems associated with the presence in the off-gas of particulates and toxic volatile metals, responsible of fouling deposits on heat exchanger surfaces.

Furthermore, owing to the modularity of the system, which allows of changing the treatment capacity of the plant, the "Molecular Dissociation" process appears potentially ideal for the municipality with very high seasonal shift of population, and consequently with a seasonal variation of MSW production. This is particularly true in the islands subjected to a high touristic flux, where it can reduce the need for the transportation of the waste stream generated by the community. This plant flexibility can also potentially satisfy the waste disposal necessity of seasonal industry.

Anyway, some of the most attractive characteristics of this technology represent also its limits, First of all, due to the low working temperature the oxidation kinetic is very slow, generally more than an order of magnitude respect to conventional thermal treatments. As a consequence, larger plants are needed to treat the same amount of waste. Furthermore, due to the intrinsic nature of the batch technology, it is impossible to maintain a constant gas quality that will follow periodic variation during the process, being more energetic at the beginning of gasification and progressively less energetic with the prosecution of the process. This implies that the gas produced from the primary chamber are not suitable as syngas, but for an efficient energy recovery it is necessary to burn this gas directly in a secondary chamber taking advantage of both its sensible and latent heat content. Also in this manner, to optimize the energy recovery, it is necessary to manage the process working with more batch gasification chambers, each one in a different reaction advancement state, as reported in Figure 3.

This reduces the flexibility and the advantages of the modularity of the process. Moreover, the use of low capacity plants, constitutes an handicap for the energy recovery because of the high amount of energy lost during the start up and the cooling down of the chambers at the end of the process.

\section{Conclusions}

The batch gasification process could represent a viable alternative for small community waste treatment allowing the reduction of emissions and cost due to waste transportation. The low working temperature of the process assures the minimization of the problems associated with the presence in the off-gas of 


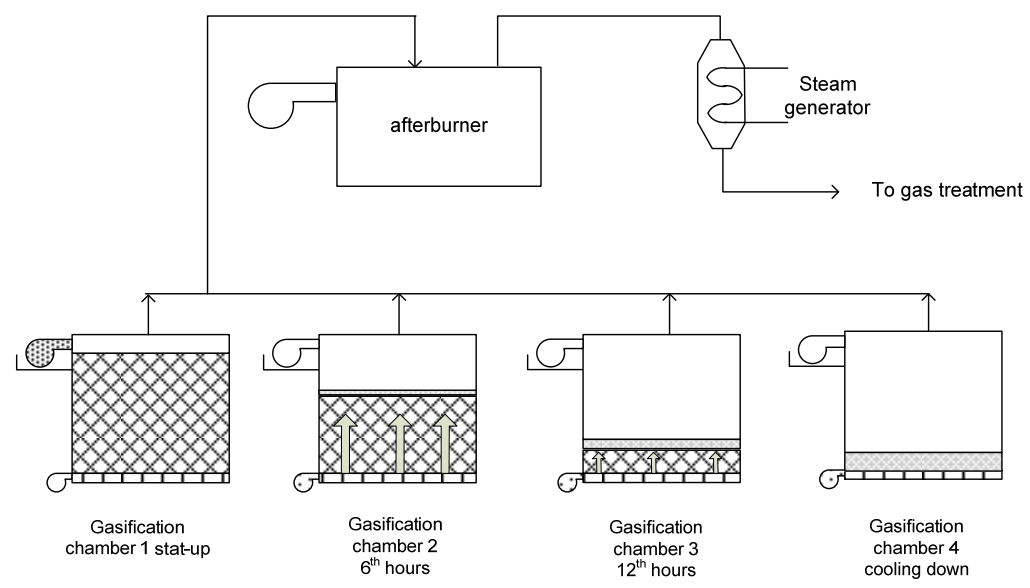

Figure 3: $\quad$ Typical process arrangement.

particulates and toxic volatile metals, responsible for fouling deposits on heat exchanger surfaces. Furthermore, owing to the mild conditions, ashes can represent a source of secondary raw materials.

However, the low working temperature represents also the main limit of this batch technology: it has, in fact, to be considered the consequent slow reaction kinetics which penalize the capacity of the process and make difficult the use of high efficiency energy recovery systems.

\section{References}

[1] Schilli J.W., Using gasification to process municipal solid waste. HDR Innovations, 12(4), 2004

[2] Energy from Waste: State-of-the-art-report. $5^{\text {th }}$ Ed. 2006. ISWA Working Group on Thermal Treatment of Waste. Rambøll: Denmark.

[3] Malcow T., Novel and innovative pyrolysis and gasification technologies for energy efficient and environmentally sound MSW disposal. Waste Management, 24, pp 53-79, 2004.

[4] Development of Environmentally Superior Technologies, Phase 2 Report. Waste management programs. NC State University. July 2005. Online. http://www.cals.ncsu.edu/waste_mgt/smithfield_projects/smithfieldsite.htm 